With regard to the amount of the fee, it appears to me that here we should find no great difficulty; much of course would depend on the station of the patient, much on the distance. Our profession has long been esteemed for its pre-eminent liberality. I am certain that my brethren, being no longer subject to the drudgery or expence of dispensing, would gladly substitute a small fee for a much larger apparent remuneration for bottles and boxes.

This plan would also apply to the poor; the guardians could name a certain sum for attendance, and let them receive tenders for the supply of drugs for the paupers within the district assigned to each practitioner.

The self-supporting dispensaries and sick societies would be no obstacles to such a system, since the medical practitioner would receive a fair remuneration for his services, and it would be his interest to encourage those who were unable to remunerate him to subscribe to such institutions.

I am fully aware that the first introduction of such a change would be attended with difficulty; but I recommend it to the serious consideration of the mem. bers of the profession, conceiving that this is the only plan that would advance the general practitioner to that station in the commonwealth for which his education, skill, acquirements, and usefulness so preeminently qualify him.

I am Gentlemen,

$$
\begin{aligned}
& \text { Your obedient servant, } \\
& \text { JAMEs TUnstal, M.D. } \\
& \text { Dawlish, Devon, Nov. 29, 1841. }
\end{aligned}
$$$$
=
$$

\section{LIGATURE OF SUBCLAVIAN ARTERY}

\section{For the Cure of Axillary Aneurism cansed by Gun- Shot Wound.}

By Josian C. Nott, M.D., Mobile, Alabama.

The following case contain some practical facts of some value, and may not be uninteresting to surgeons who are called upon to operate for aneurism:-

The subject, Mr. Christopher L. Clausel, aged 30, is a very respectable gentleman of good constitution and good habits, of Claiborne, Alabama. On August 27, 1838, while hunting, he was holding his gun (charged with small shot) by the muzzle; the gun went off accidentally, and the whole load, after passing through the wrist, lodged in the axilla ; considerable hæmorrhage ensued, both from the wrist and axilla. Dr. Watkins, who was in attendance, found it necessary to amputate the arm above the wrist, three hours after the accident; no artery required ligature, and this fact, with the hæmorrhage from the axilla, induced the belief that the axillary artery was injured by the shot.

A slough formed in the axilla, which commenced separating in four or five days. On the twelfth day, a hæmorrhage occurred from the axilla, and about a quart of blood was lost; it was commanded by compress on the wound. On the next day, a hemorrhage again occurred to about the same extent. On the sixteenth day, a third and most alarming hæmorrhage took place, completely exhausting the patient; a compress was again applied, and the hæmorrhage did not return.

On the eighteenth day, the slough separated, leaving a cavity as large as an egg, and exposing the ribs; the artery could neither be seen nor felt; the healing process soon commenced, went on rapidly, and by the middle of October it was filled up, leaving only a narrow ulcer an inch long. About this time the aneurismal tumour commenced in the axilla, and increased rapidly.

Mr. C. camo down to Mobile to consult me, and
I saw him for the first time on the $\mathbf{3 d}$ of November. On examination I found a large aneurism, filling up the axilla, and extending nearly to the clavicle; pulsations strong, and aneurismal thrill distinct. I advised tying of the subclavian artery above the clavicle, and performed the operation 'on November 27 , in the presence of Drs. Fearn, Woodcock, and Crawford. No difficulty occurred during or after the operation, and every thing went on favourably. On the twenty-sixth day after the operation, the ligature still remaining firm, I a ttached to the end of it a gum elastic thread, laid a small compress on the clavicle, drew the thread over this, and fixed it to the chest by an adhesive strip; it was thus made to exert a constant and gentle force upon the ligature. On the the thirty-first day, the ligature came away, and had it not been for this contrivance it would probably have remained a considerable time longer; although the ligature was tied so tight around the artery, that I could scarcely pass an ordinary sized pin through the loop after it eame away.

At the end of forty days the patient returned home with the wound healed, the tumour much diminished, but the pulsation, which returned two days after the operation, was still strong, and purr distinct.

I saw the patient five months after the operation, and though diminished, there was still so much pulsation in the aneurism, and the purr so distinct, as to alarm the patient.

I lost sight of the patient until April, 1841, more than two years after the operation, when I had the gratification to see him perfectly well in every respect.

Remarks. This case proves that the return of pulsation, though strong, and continuing for months, is not necessarily a cause of just alarm. The use of the gum-elastic thread to facilitate the removal of the ligature, after a reasonable time is allowed, I think is also important; for the ligature keeps the wound suppurating, and there is always danger of the pus burrowing into parts where it would do mischief. There is a case recorded in the "Medico-Chirurgical Review," where the ligature remained eighty days.-Ameriban Jour. of Med. Sciences, July, 1841.

\section{THE TENDER SYSTEM}

To THE EDITORS OF THE PROVINCIAL MEDICAL AND SURGICAL, JOURNAL.

Gentlemen,-A very good illustration of the effects of the tender system, under the surveillance of the new poor-law, was kindly furnished to the profession by Mr. Braner, of Lowestoft, in your last hebdominal. He has omitted an important part of the communication viz. the name of the successful candidate who has promised to cater for the poor at about a penny a head, "within the hundred of Mutford and Lothingland," by inserting this in your next number, you will oblige,

Your obedient servant, James Theodorick Vale, M.R.C.S.L. Birkenhead, Nov. 30, 1841.

OBITUARY.

M. Clement Desormes, Chevalier of the Legion of Honour, Professor of Chemistry at the Conservatoire des Arts et Metiers, died, at Paris, the 21st November, 1841 , at the age of 62 .

Printed by Samurc. TAYlor, of 6, Chandos-street, in the Parish of St. Paul's, Covent-garden, at his Office, No. 6, Chandos-street aforesaid; and published by JoHN C'hurchill, at his residence, No. 15, Princes-street, in the Parish of St. Anne, Westminster.-Friday, December 3, 1841 . 